\title{
Allelism between the $P$ and Stp Genes for Seedcoat Color and Pattern in Common Bean
}

\author{
Mark J. Bassett ${ }^{1}$ \\ Horticultural Sciences Department, University of Florida, Gainesville, FL 32611
}

AdDITIONAL INDEX WORDS. Phaseolus vulgaris, seedcoat genetics

\begin{abstract}
The $\boldsymbol{P}$ locus in common bean (Phaseolus vulgaris L.) can express complete absence of color (white) in seed-

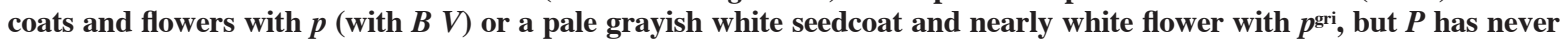
been considered a seedcoat pattern locus. Genes controlling seedcoat colors and patterns have been backcrossed into the recurrent parent 5-593 with black seedcoats and violet flowers. The cross, $p \mathrm{BC}_{3} \mathbf{5 - 5 9 3} \times t$ stpmic $\mathbf{B C}_{3} 5-593$ (black seeds with a long white micropyle stripe and fibula arcs), failed to show evidence of genetic complementation in either $F_{1}$ or $F_{2}$ progeny, leading to the hypothesis that $\boldsymbol{P}$ and $S t p$ are allelic. Five cross combinations between two recessive $P$ alleles $(p$ $\mathrm{BC}_{3} 5-593$ and $\left.p^{\text {gri }} \mathrm{BC}_{3} 5-593\right)$ and three recessive alleles at the stippled seedcoat gene $\operatorname{Stp}\left(\operatorname{stp} \mathrm{BC}_{3} 5-593, s^{\mathrm{hbw}} \mathrm{BC}_{3} 5-593\right.$, and $s t p^{\text {mic }} \mathrm{BC}_{3}$ 5-593) expressed no genetic complementation in seedcoats and flowers of $\mathrm{F}_{1}$ progeny and confirmed the allelism hypothesis. New gene symbols are proposed for the recessive alleles at $S t p$, viz., $p^{\text {stp }}$ for $s t p, p^{\text {hbw }}$ for $s t p^{\text {hbw }}$ and $p^{\text {mic }}$ for $s t p^{\text {mic }}$. The dominance order at $P$ is $P>p^{\text {mic }}>p^{\text {hbw }}>p^{\text {stp }}>p^{\text {gri }}>p$. Crosses were made between $t$ self-colored $\mathrm{BC}_{3} 5-593$ and three other parents $-p^{\text {stp }} \mathrm{BC}_{3}$ 5-593, $p^{\text {hbw }} \mathrm{BC}_{3}$ 5-593, and $p^{\text {mic }} \mathrm{BC}_{3}$ 5-593 - to explore interactions between the pattern genes $T$ and $P$; and segregation for seedcoat patterns in $\mathrm{F}_{2}$ was discussed. The hypothesis was proposed that the $T$ locus regulates expression at $P$, or the biosynthetic step regulated by $P$.
\end{abstract}

Prakken (1970) summarized the genetics of seedcoat color (other than the red colors) in common bean (Phaseolus vulgaris L.), and he reconciled the different gene symbols used by various researchers for the same gene. Subsequently, Prakken (1972) published his extensive work with red seedcoat colors and organized the entire body of seedcoat color genetics (Prakken, 1970, 1972) into two tables, one for the yellow-black series of colors and the other (a text table) for the red colors. The tables present the colors expressed with genotype $P / P$ together with all combinations of the other eight genes $(C, R, D, J, G, B, V$, and $R k)$ in the seedcoat color system. Two of the eight genes, the pattern gene $C$ and the gene $R$ for dominant red color, are very tightly linked (Prakken, 1972). To express the nearly unbreakable linkage betwen the two genes, they are usually presented in brackets, $[C R]$ (Bassett, 1991). Recently, a ninth gene ( $G y$ for greenish yellow) for seedcoat color was reported by Bassett et al. (2002), but this gene is known to be closely linked to $C$ (McClean et al., 2002) and with further experimental work may prove to be another gene (like $R$ ) located within the complex $C$ locus as described by Prakken (1974). Also, the $D$ locus was recently discovered to be allelic with the $Z$ gene, which interacts with $t$ ( $T$ for totally colored seedcoat) to produce various partly colored seedcoat patterns (Bassett et al., 1999).

\section{Seedcoat Color Genetics}

The genetic stocks employed in this paper all carried the genotype $[C r] Z J G B V R k$, which expresses black seedcoat except where altered by $p$ or other pattern genes. The $C$ locus has a very large multiple allelic series of dominant genes controlling seedcoat patterns, and $c^{\mathrm{u}}$ expresses a cartridge buff (pale beige) seedcoat. Patterns controlled by $C$ have a dark pattern color contrasted with cartridge buff as the light pattern color, unless modified by alleles for recessive red colors controlled by the red kidney locus $R k$. The genotype $C / c$ expresses subtle seedcoat mottling effects, whereas

Received for publication 26 Oct. 2002. Accepted for publication 19 Feb. 2003 This research was supported by the Florida Agricultural Experiment Station and a T-STAR grant, and approved for publication as journal series no. R-09014. ${ }^{1}$ Professor. $c / c$ genotypes have slightly paler colors than the same background genotypes with $C / C$. The $J$ locus (with $j / j$ ) expresses loss of color in the hilum ring, reduced color expression in the corona, and loss of seedcoat shininess. According to Bassett (1996a), $j / j$ also expresses immature seedcoat colors, i.e., a paler version of whatever color the seedcoat color genotype with $J$ would have expressed. The $Z$ locus interacts with $J$ to produce (with $j / j z / z$ ) the loss of color in the corona region of the seedcoat in addition to the hilum ring. The genes $G, B$, and $V$ are color modifying genes: $G$ (from Gelbe, yellow in German) for yellow with $G b v ; B$ for brown expressing mineral brown with $G B v$ and buffy citrine with $g B v$; and $V$ for violet to black (anthocyanin pigments) expressing dark brown violet with $G b V$ and black with $G B V$. With $g b v$, the seedcoat is shamois. The red kidney locus $R k$ controls recessive red seedcoat colors testaceous (light red kidney) and garnet brown (dark red kidney), which have the most stable expression with $c^{u}$. The gene $R$ expresses dominant red (oxblood) color, which is slightly bluer than garnet brown (Bassett, 1998a).

\section{History of the $P$ Locus}

The recessive allele $p$ expresses (with genotype $p / p$ ) a white seedcoat. Shull (1908) was the first to report the existence of a dominant gene necessary to express seedcoat color, and Emerson (1909) gave this gene the symbol $P$. Lamprecht (1936) discovered a second ground factor gene designated griseoalbus (for gray-white seedcoat), which he gave the gene symbol Gri. The term ground factor means that Gri (and $P$ ) are necessary for seedcoat color expression. Bassett (1994) discovered that Gri is allelic with $P$, and gave the recessive allele the gene symbol $p^{\text {gri }}$. The current view of the role the $P$ gene plays in seedcoat chemistry will be given at the end of the paper.

Bassett (1996b) discovered a new seedcoat gene (with gene symbol Stp for stippled) for pattern in seedcoats and flowers and described two recessive alleles at this locus stp and $s t p^{\text {hbw. A third }}$ recessive allele, $s t p^{\text {mic }}$, was later reported by Bassett (1998b). Allelism tests were made between Stp and the two other genes known to express seedcoat pattern, viz., $C$ and $T$, and found that Stp was 

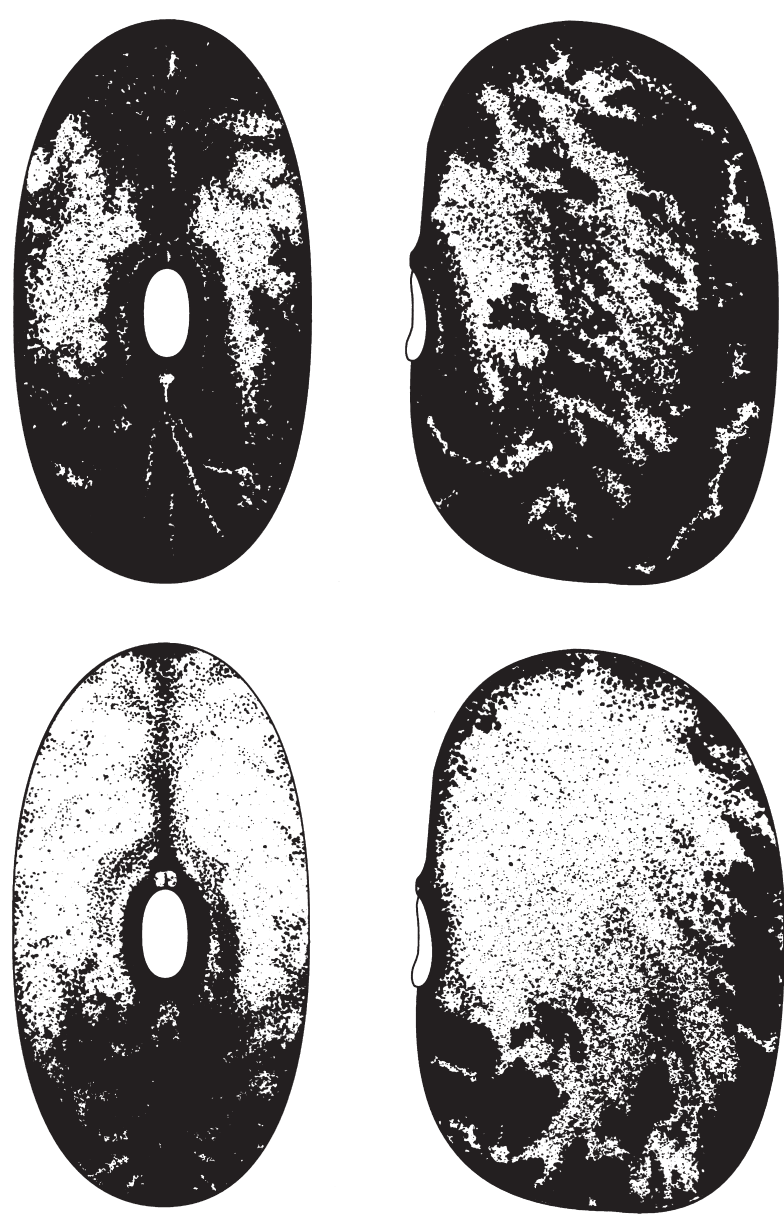

Fig. 1. Drawings of seeds with the stippled pattern controlled by $p^{\text {stp }}$ (formerly $s t p)$ : upper seeds show the most extensive dark pattern color; lower seeds show the least extensive dark pattern color.

nonallelic (Bassett, 1996b). The $P$ locus was not known to produce patterns in seedcoats. This paper presents evidence for the allelism of $P$ and St $p$ and investigates the dominance relationshps among five recessive genes: $s t p, s t p^{\text {hbw }}, s t p^{\text {mic }}, p$, and $p^{\text {gri }}$. The paper also presents descriptions of interactions of $t$ with $s t p$ and $s t p^{\text {hbw }}$ as expressed in altered seedcoat patterns.

\section{Materials and Methods}

Materials AND test Crosses. The genetic stocks used were constructed by backcrossing selected recessive marker genes for seedcoat color or pattern into the recurrent parent 5-593, a Florida dry bean breeding line with black seedcoats due to genotype $T$ $P[C r] Z J G B V R k$ (Bassett, 2001). The $P$ locus genetic stocks included $p \mathrm{BC}_{3}$ 5-593 [white seed with (pale yellowish) brown micropyle stripe] and $p^{\text {gri }} \mathrm{BC}_{3}$ 5-593 (light gray with $B V$ ). The $S t p$ locus genetic stocks included stp $\mathrm{BC}_{3}$ 5-593 (Fig. 1), stphbw $\mathrm{BC}_{3}$ 5-593 (Fig. 2), stp ${ }^{\text {mic }} \mathrm{BC}_{3}$ 5-593 (Fig. 3), and $t$ stpmic $\mathrm{BC}_{3}$ 5-593 (Fig. 4).

To test for allelism between $P$ and $S t p$, the cross $p \mathrm{BC}_{3} 5-593 \times t$ stpmic $\mathrm{BC}_{3} 5-593$

Fig. 3. Ventral view of the seedcoat pattern (white micropyle stripe) produced by $p^{\text {mic }}$ (formerly $s t p^{\text {mic }}$ ).
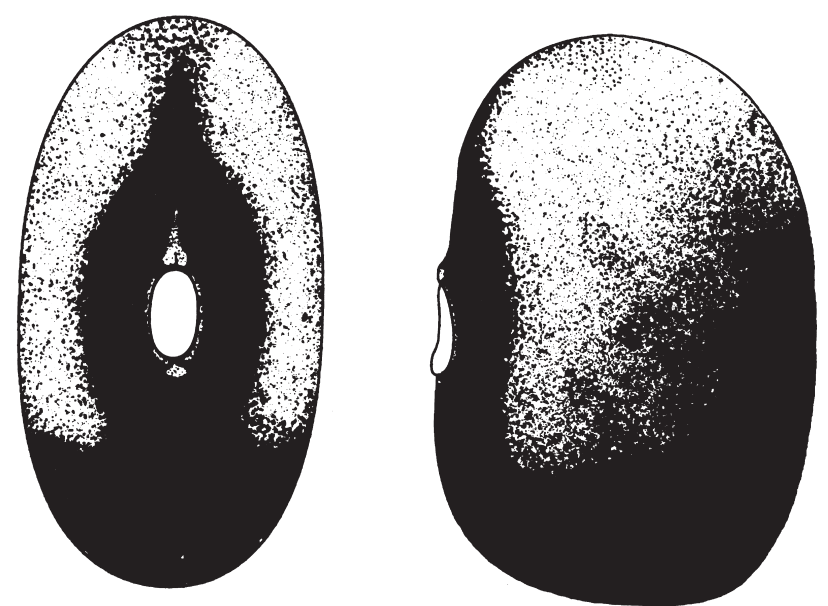

Fig. 2. Drawings of seeds with the stippled pattern controlled by $p^{\text {thw }}$ (formerly stp $\left.{ }^{\mathrm{hbw}}\right)$.

was made in Fall 2000, and the $\mathrm{F}_{2}$ generation was grown in the field in Spring 2001. Data were recorded for color and pattern of seedcoats and flowers. To test for the interactions of $t$ with stp and $s t p^{\text {hbw }}$, the crosses $t$ self-colored $\mathrm{BC}_{2} 5-593 \times$ stp $\mathrm{BC}_{3} 5-593$ and $s t p^{\text {hbw }} \mathrm{BC}_{3} 5-593$ were made in Fall 2000, and the $\mathrm{F}_{2}$ generation was grown in the field in Spring 2001. Data were recorded for color and pattern of seedcoats and flowers.

To further test for allelism between $P$ and Stp and establish the dominance order among the putative five recessive alleles at $P$, the following test crosses were made: $p \mathrm{BC}_{3} 5-593 \times$ stp $\mathrm{BC}_{3}$ 5-593, $p$ $\mathrm{BC}_{3} 5-593 \times s t p^{\text {hbw }} \mathrm{BC}_{3} 5-593, p \mathrm{BC}_{3} 5-593 \times s t p^{\text {mic }} \mathrm{BC}_{3} 5-593, p^{\text {gri }}$ $\mathrm{BC}_{3} 5-593 \times s t p^{\text {hbw }} \mathrm{BC}_{3} 5-593$, and $p^{\text {gri }} \mathrm{BC}_{3} 5-593 \times$ stp ${ }^{\text {mic }} \mathrm{BC}_{3} 5-$ 593. The $F_{1}$ progenies from the test crosses between the two known recessive alleles at $P$ and the three known recessive alleles at Stp were grown in the greenhouse in Winter 2002, and descriptive data were recorded for color and pattern of seedcoats and flowers.

\section{Results and Discussion}

For the cross $p \mathrm{BC}_{3} 5-593 \times t$ stpmic $\mathrm{BC}_{3} 5-593$, the $\mathrm{F}_{1}$ seeds expressed the white micropyle stripe pattern on black seeds typical of genotype $s t p^{\text {mic }}$ (Fig. 3). The lack of complementation between $P$ and Stp supported the hypothesis of nonallelism. The segregation observed in the $\mathrm{F}_{2}$ generation for flower color and seedcoat color
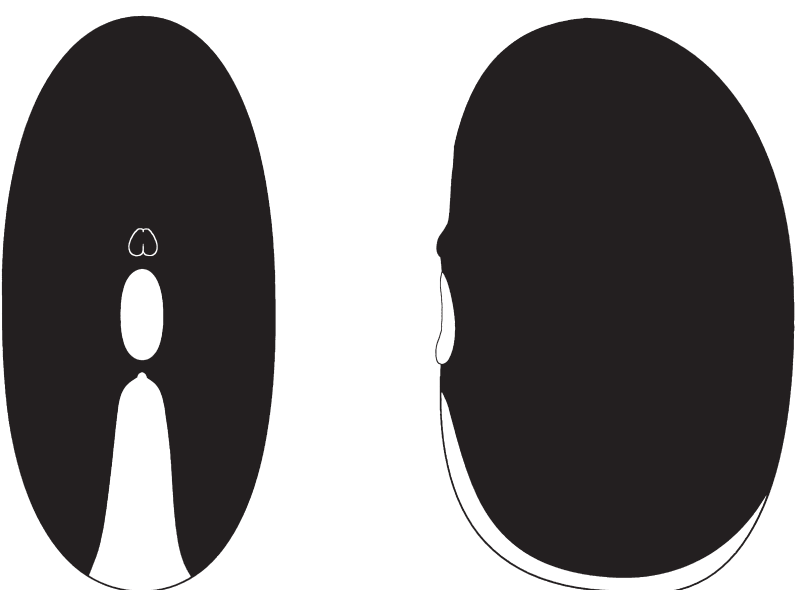

Fig. 4. (left) Ventral view of the long micropyle stripe seedcoat pattern (long white micropyle stripe) produced by $t p^{\text {mic }}$ ( $p^{\text {mic }}$ formerly $\left.s t p^{\text {mic }}\right)$. (right) Side view of the long micropyle stripe of $t p^{\text {mic }}$. 
Table 1. Segregation for flower color and seedcoat pattern in the $\mathrm{F}_{2}$ from the cross $p \mathrm{BC}_{3} 5-593(T p) \mathbf{X} t s t p^{\text {mic }} \mathrm{BC}{ }_{3} 5-593\left(t p^{\text {mic }}\right)$.

\begin{tabular}{|c|c|c|c|c|c|c|}
\hline \multirow{2}{*}{$\begin{array}{l}\text { Violet flowers } \\
T /-p^{\text {mic/- }}\end{array}$} & \multicolumn{4}{|c|}{ White flowers } & & \\
\hline & $t / t p^{\text {mic }} /-$ & $T / T p / p$ & $T / t p / p$ & & & \\
\hline Black seed & Black seed & White seed & White seed & & & \\
\hline with white & with white $\mathrm{MS}^{\mathrm{z}}$ & with brown & with brown & $t / t p / p$ & $\chi^{2}$ & \\
\hline $\mathrm{MS}^{\mathrm{z}}$ & and fibula arcs & $\mathrm{MS}^{\mathrm{z}}$ & two-pointsy & White seed & $9: 3: 1: 2: 1^{w}$ & $P$ \\
\hline 239 & 75 & 34 & 62 & 37 & 6.469 & 0.17 \\
\hline
\end{tabular}

${ }_{\mathrm{z}}^{\mathrm{MS}}=$ micropyle stripe.

yTwo points or stripes on either side of the micropyle.

wFor the genotype $t / t \mathrm{p} / \mathrm{p}$, the observed value of 37 was a surplus over the expected value of 27.94 , giving $\chi^{2}=2.94$. Similarly, the surplus of $T / T$ $p / p$ plants gave $\chi^{2}=1.32$. For the comparison $T /-p^{\text {mic }}-$ vs. $t / t p^{\text {mic } /-}, T /-p / p$ and $t / t p / p$, the data 239,208 gave $\chi^{2}(9: 7)=1.406, P=0.24$, and for

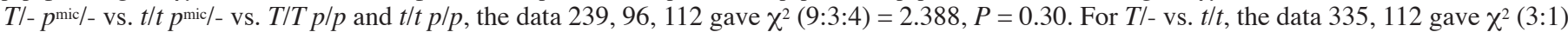
$=0.001, P=0.98$. For $p^{\text {mic }} /$ - vs. $p / p$, the data 314,133 (a surplus over the expected 111.75) gave $\chi^{2}(3: 1)=5.388, P=0.02$.

or pattern is presented in Table 1. The observed data involved five phenotypic classes and fit the proposed genetic model, but the chi-square test for segregation at the $P$ locus gave a significant deviation from expected values (Table 1). There was a surplus of $p / p$ plants and a shortage of $p^{\text {mic/- }}$ plants. This shortage may be due to lethality of $p^{\text {mic }}$ genotypes.

Phenotype of $\boldsymbol{p} / \boldsymbol{p}^{\text {stp. }}$. For the $\mathrm{F}_{1}$ plants from the cross $p \mathrm{BC}_{3} 5$ $593 \times \operatorname{stp} \mathrm{BC}_{3} 5-593$, the wings of the flowers were white, but the banner petal had the same pattern as $s t p \mathrm{BC}_{3} 5-593$ (Fig. 5) except that the color was distinctly paler, and the violet banner tip was more narrow. The $\mathrm{F}_{2}$ seeds had the same pattern as stp (Fig. 1), but the dotting on the micropyle end of the seed was more dispersed. Thus, stp is an allele at $P$ and is almost completely dominant to $p$. I propose the new gene symbol $p^{\text {stp }}$ for $s t p$.

Phenotype of $\boldsymbol{p} / \boldsymbol{p}^{\text {hbw }}$. For $\mathrm{F}_{1}$ plants from the cross $p \mathrm{BC}_{3}$ 5-593 $X s t p^{\text {hbw }} \mathrm{BC}_{3} 5-593$, the wings of the flowers were pale violet with a small patch of white in the center. The violet color of the wings is intermediate between the Cobalt-violet (Bassett et al., 1990) of $V / v$ and the violet of the wing periphery of stp. The banner petal was white except for a band of violet at the tip. Thus, the flowers were very similar in appearance to the $s t p^{\text {hbw }}$ parent (Fig. 5). The $\mathrm{F}_{2}$ seeds had the same pattern as stp $^{\text {hbw }}$ (Fig. 2) except that the near-white color was paler and the dotting on the micropyle end of the seed was more dispersed. Thus, stphbw is an allele at $P$ and is almost completely dominant to $p$. I propose the new gene symbol $p^{\text {hbw }}$ for $s t p^{\text {hbw }}$.

Phenotype of $p / p^{\text {mic. For }} \mathrm{F}_{1}$ plants from the cross $p \mathrm{BC}_{3}$ 5-593 $\mathrm{X} s t p^{\text {mic }} \mathrm{BC}_{3}$ 5-593, the flower color was Bishops-violet (Bassett et al., 1990) like $s t p^{\text {mic }}$, but the wings had a white peripheral band $\approx 0.5 \mathrm{~mm}$ wide or less. The $\mathrm{F}_{2}$ seeds had the same pattern as $s t p^{\text {mic }}$ (Fig. 3). Thus, $s t p^{\text {mic }}$ is an allele at $P$ and is dominant to $p$. I propose the new gene symbol $p^{\text {mic }}$ for $s t p^{\text {mic }}$

PhenotyPe of $\boldsymbol{p}^{\text {gri }} / \boldsymbol{p}^{\text {hbw. }}$. For $\mathrm{F}_{1}$ plants from the cross $p^{\text {gri }} \mathrm{BC}_{3} 5$ -
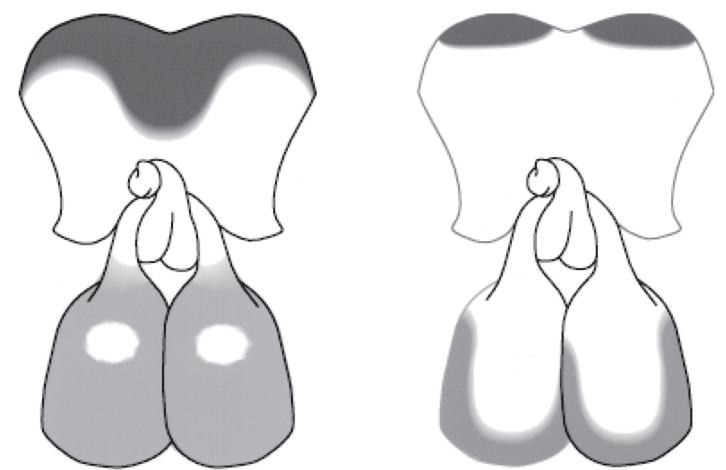

Fig. 5. The flower on the left illustrates the color pattern controlled by $p^{\text {hbw }}$ (formerly $s t p^{\text {hbw }}$ ); the flower on the right illustrates the color pattern controlled by $p^{\text {stp }}$ (formerly $\left.s t p\right)$.
$593 \times s^{\text {hbw }} \mathrm{BC}_{3} 5-593$, the wings of the flowers were pale violet (same as $p \mathrm{BC}_{3} 5-593 \times s t p^{\text {hbw }} \mathrm{BC}_{3} 5-593$ ) with a small patch of near-white color in the center and a white peripheral band $\approx 0.5$ $\mathrm{mm}$ wide or less. The banner petal had a violet banner tip similar to $s t p^{\text {hbw }}$ (Fig. 5), but with stronger color. The seedcoat pattern of these plants is the same as $s t p^{\text {hbw }}$ (Fig. 2) except that the near-white color is paler and the micropyle end of the seed has more dispersed dotting. Thus, $s t p^{\text {hbw }}$ is almost completely dominant to $p^{\text {gri }}$.

PhenotyPe OF $\boldsymbol{p}^{\text {gri }} / \boldsymbol{p}^{\text {mic }}$. For $\mathrm{F}_{1}$ plants from the cross $p^{\text {gri }} \mathrm{BC}_{3}$ 5-593 $\mathrm{X} s t p^{\text {mic }} \mathrm{BC}_{3} 5-593$, the flower color was Bishops-violet like $s t p^{\text {mic }}$, but the wings had a white peripheral band $\approx 0.5 \mathrm{~mm}$ wide or less. The seedcoats had the same pattern as $s t p^{\text {mic }}$ (Fig. 3) except that the near-white micropyle stripe is a little longer and more stable from seed to seed. Thus, $s t p^{\text {mic }}$ is dominant to $p^{\text {gri }}$.

The above data support the hypothesis that the $P$ locus has five recessive alleles, each with a unique combination of effects on color pattern in the flowers and seedcoats. Although the test cross $p^{\text {gri }} \mathrm{BC}_{3} 5-593 \times$ stp $\mathrm{BC}_{3} 5-593$ was not made, the dominance of stp over $p^{\text {gri }}$ is assumed because of the dominance of $s t p$ over $p$. The dominance order $s t p^{\text {mic }}>s t p^{\text {hbw }}>s t p$ was previously established (Bassett, 1998b); and similarly the dominance order $p^{\text {gri }}>p$ was previously established (Bassett, 1994). Thus, the dominance order, using the new gene symbols for the former Stp locus, is $P>p^{\text {mic }}$ $>p^{\text {hbw }}>p^{\text {stp }}>p^{\text {gri }}>p$.

Now that the previous gene $s t p^{\text {mic }}$ is known to be an allele at $P$ with new gene symbol $p^{\text {mic }}$, the data presented in a previous paper (Bassett, 1998b) for interactions stp ${ }^{\text {mic }}$ with $t$ and $z$ need to be interpreted in a new light. Using the new gene symbol for $s t p^{\text {mic }}$, the genotype $t p^{\text {mic }}$ extends the white micropyle stripe around the
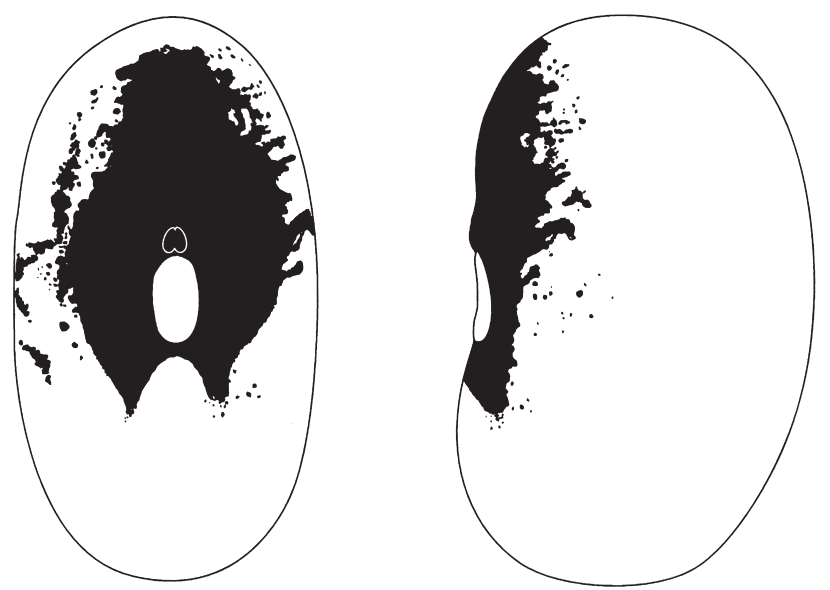

Fig. 6. (left) Ventral view of the seedcoat pattern produced by $t z p^{\text {mic }}\left(p^{\text {mic }}\right.$ formerly $s t p^{\text {mic }}$. (right) Side view of the same genotype effect, primarily the elimination of the colored micropyle stripe that would appear with $t z P$ (virgarcus). 

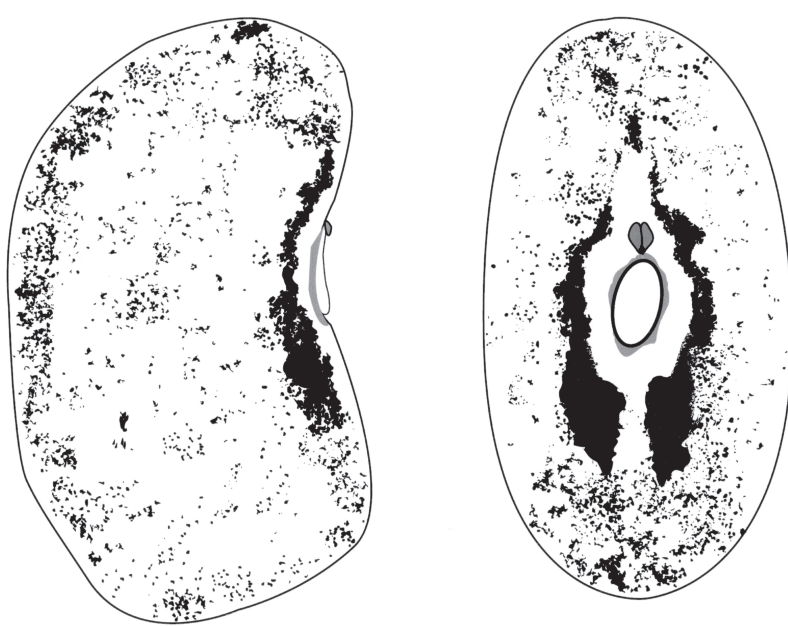

Fig. 7. (left) Side view of the seedcoat pattern produced by $t p^{\text {hbw }}\left(p^{\text {hbw }}\right.$ formerly $\left.s t p^{\mathrm{hbw}}\right)$. (right) Ventral view of the same genotype effect; the only true white occurs in the corona region and around and above the caruncula, whereas the other white areas have a light gray appearance in real seeds due to fine gray dots (not shown) that are only visible with a $15 \times$ monocle.

end of the seed (Fig. 4) and $t z p^{\text {mic }}$ restricts color expression to a virgarcus pattern (Bassett, 1996c) without a micropyle stripe (Fig. 6 ). The simplest hypothesis for the gene actions involved is that $t$, and its modifier $z$, regulate the expression at $P$ or the biosynthetic step regulated by $P$ (P. McClean, personal communication). Genotype $t z$ expresses a precisely additive restriction to the pattern of color expressed by $p^{\text {mic. }}$.

Additional research was performed to explore the interactions of $t$ with the other two recessive alleles at Stp. The cross $t$ selfcolored $\mathrm{BC}_{2} 5-593 \times$ stp $\mathrm{BC}_{3} 5-593$ ( $p^{\mathrm{stp}}$ ) segregated in $\mathrm{F}_{2}$ for $t p^{\mathrm{stp}}$ recombinants at the expected frequency (data not shown). The seedcoat pattern of $t p^{\text {stp }}$ was not different from $T p^{\text {stp. The cross } t}$ self-colored $\mathrm{BC}_{2} 5-593 \times$ stphbw $\mathrm{BC}_{3} 5-593$ ( $p^{\text {hbw }}$ ) segregated in $\mathrm{F}_{2}$ for $t p^{\text {hbw }}$ recombinants at the expected frequency (data not shown). The seedcoat pattern of $t p^{\text {hbw }}$ (Fig. 7) differs from $T p^{\text {hbw }}$ by having much less dark pattern color and more dispersed black dotting. The white seedcoat areas outside the corona (Fig. 7) actually have a secondary pattern of pale gray dots (not shown to simplify the illustration), which give an overall light gray appearance to the seed. The pale gray dot pattern can only be observed to consist of separate dots with $15 \times$ magnification.

BiocheMistRy OF $\boldsymbol{P}$ IN RELATION TO SEEDCOAT COLOR. The biochemistry of the $P$ gene is under investigation at Michigan State University (G. Hosfield, personal communication). This research group regards $P$ as a candidate gene for the enzyme, flavanone 3hydroxylase $(\mathrm{F} 3 \mathrm{H})$ (unpublished data). $\mathrm{F} 3 \mathrm{H}$ converts flavanone to a dihydroflavonol called dihydrokaempferol, which is then converted to kaempferol. Dihydroflavonols are the precursors to all color compounds, and in alfalfa (Medicago media), $\mathrm{F} 3 \mathrm{H}$ is involved in the synthesis of anthocyanins and flavonols (G. Hosfield, personal communication).

Biochemical investigation of $P$ at North Dakota State University also indicates that $P$ is a candidate gene for the enzyme $\mathrm{F} 3 \mathrm{H}$ (P. McClean, personal communication). His laboratory has cloned a fragment of $\mathrm{F} 3 \mathrm{H}$, which spans from exon 2 across intron 2 and just into exon 3 . They sequenced 23 common bean genotypes [named cultivars, including 'UI-114' (with $P$ ) and 'Aurora' (with $p)$ ] across this region of the gene, and all the genotypes were monomorphic (P. McClean, personal communication). At this early stage in the investigation, one can only speculate as to the location of the polymorphism that expresses as different alleles at $P$. One likely site is the promoter region of the gene (P. McClean, personal communication).

The research at these two laboratories on the role of $P$ in the biochemistry of seedcoat colors remains unpublished. Because common bean has no genetic transformation system, proving the hypothesis of $P$ as a candidate gene for $\mathrm{F} 3 \mathrm{H}$ will be difficult. Perhaps reviewers will accept the results of polymorphism studies as providing the necessary proof for a species without a transformation system (P. McClean, personal communication).

\section{Literature Cited}

Bassett, M.J. 1991. A revised linkage map of common bean. HortScience 26:834-836.

Bassett, M.J. 1994. The griseoalbus (gray-white) seedcoat color is controlled by an allele ( $p$ gri) at the $P$ locus in common bean. HortScience 29:1178-1179.

Bassett, M.J. 1996a. The margo (mar) seedcoat color gene is a synonym for the Joker (j) locus in common bean. J. Amer. Soc. Hort. Sci. 121: $1028-1031$.

Bassett, M.J. 1996b. New genes, stp and stphbw, for flower and seedcoat pattern in common bean. J. Amer. Soc. Hort. Sci. 121:388-392.

Bassett, M.J. 1996c. Inheritance of the partly colored seedcoat pattern, bipunctata, in common bean. J. Amer. Soc. Hort. Sci. 121:1032-1034.

Bassett, M.J. 1998a. A test cross protocol for determining the genotype of dark red seedcoat colors in common bean. J. Amer. Soc. Hort. Sci. 123:1048-1052.

Bassett, M.J. 1998b. A third recessive allele, $s t p^{\text {mic }}$, for seedcoat pattern at the Stp locus in common bean. J. Amer. Soc. Hort. Sci. 123:404-406.

Bassett, M.J. 2001. Inheritance of the Fib gene (from 5-593) for fibula arcs pattern of partly colored seed coat in the background genotype $t P[\mathrm{Cr}]$ Z J G B V Rk. Annu. Rpt. Bean Improv. Coop. 44:171-172.

Bassett, M.J., L.B. Xue, and L.C. Hannah. 1990. Flower colors in common bean produced by interaction of the $S a l$ and $V$ loci and a gametophyte factor $G a$ linked to Sal. J. Amer. Soc. Hort. Sci. 115:1029-1033.

Bassett, M.J., C. Shearon, and P. McClean. 1999. Allelism found between two common bean genes, hilum ring color $(D)$ and partly colored seedcoat pattern $(Z)$, formerly assumed to be independent. J. Amer. Soc. Hort. Sci. 124:649-653.

Bassett, M.J., R. Lee, C. Otto, and P.E. McClean. 2002. Classical and molecular genetic studies of the strong greenish yellow seedcoat color in 'Wagenaar' and 'Enola' common bean. J. Amer. Soc. Hort. Sci. 127: $50-55$.

Emerson, R.A. 1909. Factors for mottling in beans. Amer. Breed. Assn. 5:368-376.

Lamprecht, H. 1936. Zur Genetic von Phaseolus vulgaris. XIII. Ein neues Grundgen für Testafarben, ein weiteres Testafarbgen sowie etwas über Blütenfarben. Hereditas 22:241-268.

McClean, P.E., R.K. Lee, C. Otto, P. Gepts, and M.J. Bassett. 2002. Molecular and phenotypic mapping of genes controlling seed coat pattern and color in common bean (Phaseolus vulgaris L.). J. Hered. 93:148-152.

Prakken, R. 1970. Inheritance of colour in Phaseolus vulgaris L. II. Acritical review. Meded. Landbouwhogeschool Wageningen 70-23:1-38.

Prakken, R. 1972. Inheritance of colours in Phaseolus vulgaris L. III. On genes for red seedcoat colour and a general synthesis. Meded. Landbouwhogeschool Wageningen 72-29:1-82.

Prakken, R. 1974. Inheritance of colours in Phaseolus vulgaris L. IV. Recombination within the 'complex locus $C$ '. Meded. Landbouwhogeschool Wageningen 74-24:1-36.

Shull, G.H. 1908. A new Mendelian ratio and several types of latency. Amer. Nat. 42:433-451. 